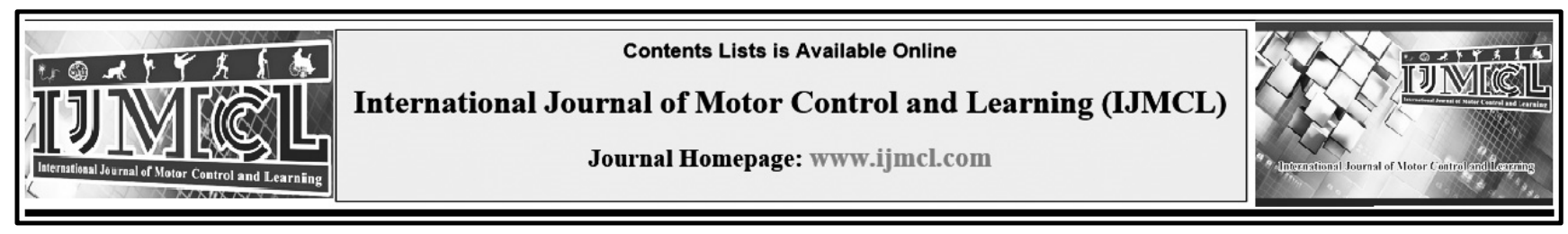

\title{
Psychological Skills Profile of Iranian Elite Swimmers
}

\author{
Negar Moghadama, Mohammad Reza Shahabi Kaseb ${ }^{\text {b* }}$, Zahra Stirib ${ }^{\mathrm{b}}$, Abdolreza Riahi ${ }^{\mathrm{c}}$
}

\author{
${ }^{a}$ M.A in Sport Science, Hakim Sabzevari University, Faculty of Sport Science, Sabzevar, Iran \\ ${ }^{\mathrm{b}}$ Assistant Professor in Motor Behavior, Hakim Sabzevari University, Faculty of Sport Science, Sabzevar, Iran \\ ${ }^{\mathrm{c}}$ M.A in Sport Managment, Swimming Federation, Tehran, Iran
}

\begin{tabular}{l}
\hline Keywords \\
\hline Psychological Skills \\
Elite Swimmers \\
Individual Sport
\end{tabular}

Mohammad Reza Shahabi Kaseb,

Email: mr.shahabi@hsu.ac.ir

Received: 2020/07/01

Accepted: 2020/10/05

Published: 2020/11/05

\begin{abstract}
Background: One of the most important factors affecting the optimal implementation of motor skills and reaching the peak of performance in sports and competitive environments is the use of psychological skills.
\end{abstract}

Objective: The aim of the present study was to compare the psychological skills of Iranian elite swimmers based on competitive experience, gender, age and swimming distance.

\begin{abstract}
Methods: For this purpose, 93 elite swimmers were selected as available subjects. The Amst 3 questionnaire was used to measure the psychological skills of swimmers and then the findings were analyzed using SPSS software.
\end{abstract}

Results: The results of independent t-test and U-Man Whitney showed that there was no significant statistical difference between the psychological skills of Iranian elite swimmers based on competitive experience, age, gender and distance of swimming.

Conclusion: It seems that Iranian elite swimmers have learned psychological skills through natural learning, and this has made the level of psychological skills of Iranian elite swimmers about the same. Therefore, the need to use psychological interventions is important for elite Iranian swimmers.

\section{Introduction}

Nowadays, with the advancement of psychology, the discussion of the effect of mental skills in the implementation of sports skills has become very important and psychological factors that contribute to sports performance have become widespread interest of athletes, coaches and sports psychologists (Gokiardi 2008). In this regard, Leon (2002) and Jones (1990) state that in high-level sports activities (or at least many sports), there is not much difference between athletes in terms of skill and physical level and What distinguishes the winner from the loser is the difference in the psychological characteristics of the athletes.
Athletes with different levels of skill and competitive experience have different psychological profiles (Kags, 1996; Bebetsas, 2015). So that the psychological profile of elite athletes can be properly distinguished from nonelite athletes (Mahindoost, 2001). Studies on the psychological skills of group disciplines confirm this issue. Bahram (2010), Taghian (2001) and mihandost (2001) compared some of the psychological skills of elite and non-elite volleyball players.

The results of this study showed that elite volleyball players have higher levels of concentration, self-confidence, mental energy 
regulation, mental imagery and goal setting than non-elite players. This is the case in research on athletes in various individual disciplines such as archery by Bebetsas (2015); Wrestling (Mirzaei et al., 2007); Track and Field (quoted by Behlool, 1394); Karate (Isfahani, 1392); Judo (Commercial, 2012); Gymnastics (Claire, 2003); Table tennis (Kiesildeg, 2012) has also been approved. In this regard, Bebetsas (2015) in a study evaluated the psychological skills of elite Greek archers based on their years of competitive experience. The results showed that more experienced athletes had more self-confidence and focus and tended to let go of worries and stressful performances. In a metaanalysis of the psychological strategies of Greek runners, Katiskas et al. (2009) concluded that elite athletes, in comparison with non-elite athletes, had considerable control over emotions, targeting, imagery, activation, and calmness. Claire (2003) examined executive strategies for psychological skills in elite women gymnasts at two competitive levels. The results of Claire's research showed that international gymnasts used broader and more precise strategies than their national counterparts. In this regard, the results of Kiesildeg's (2012) study showed that basketball players with more sports experience used more drawing skills compared to their less experienced counterparts.

Some studies have attributed the "age group" factor to the existence of some differences in psychological skills between athletes in different disciplines (Taylor et al., 2008; Monroe et al., 2012; Gazzi et al., 2009).

In this regard, Monroe et al. (2012) demonstrated more use of imagery skills for "young athletes" compared to adults, Gazzi et al. (2009) more trait anxiety in "adult athletes" than young people And Bebetsas and Antonio (2003) the ability to respond better to stress "adult" in the face of adversity than adolescent athletes.

Gender as an important interpersonal factor in competitive sports can affect the psychological skills of athletes (Behlool et al., 2015). In this regard, Marcus, Taylor, and Christina (2008) studied performance strategies in American Olympic athletes and in this study, comparing men and women, concluded that women were more positive about self-talk during competition, While during training, no difference was observed between men and women. Sotoudeh et al. (2012) also compared the selected psychological skills between male and female elite athletes with nonelite Taekwondo athletes and stated that there is a difference between men and women only in activating arousal. Katiskas et al. (2009) also stated that male athletes were better than female athletes in calming and controlling emotion (quoted in Behlool, 2015).

According to Fletcher (2003), Hunton (1996), Auckland, Paolo (2012) and Weinberg (2009), without a doubt, one of the most important factors in the optimal performance of swimmers in different competitive situations, will be applying psychological skills and strengthening them in opportunity training. Also, Paolo (2012) and Hunton and Jones (1996) state that practicing mental skills provides an opportunity to predict the success and readiness of swimmers before being in a competitive position and to maintain self-control at the desired level and increase self-confidence. 
Hill and Whitehouse (1998) and Hunton and Jones (1996) also stated that swimmers in order to achieve high levels of performance, need to improve their psychological skills and strategies, including goal setting, imagery, and self-talk, to control competitive anxiety as Execution facilitators. in this regard, Weinberg (2009), Burton (1992) and Bugsy (1982) stated that goal setting (short-term and long-term) and commitment to goals make swimmers focus on their program and orientation and Makes easier the achievement process to goals and has a positive effect on swimmers' performance.

Research findings of Mark (2007), Welp and Kiel (1987). Christian Bam (1987) aimed to determine the differences in the psychological characteristics of elite and non-elite swimmers, showed that elites compared to non-elite individuals use a greater extent cognitive strategies including a tendency to participate more in intellectual activities (reduction of negative thoughts And Anxiety (Mark, 2007), mental skills (mental and physical program for each race) to better prepare for the pressure of competition (Wolp and Kiel, 1987) and self-regulatory behaviors such as: relaxation exercise, appropriate reaction And use coping with stress and attention control (Christian Bam, 1987).

Similarly, Fletcher and Hunton (2001) in their study aimed to investigate the relationship between the use of mental skills in swimmers and response to competitive anxiety, reported that swimmers who use high-level mental relaxation skills, compared to those who use these skills less are better able to overcome their anxiety in competitions (23).

It seems that in order to understand the strengths and weaknesses of elite swimmers in applying mental skills and as a result of training planning, it is necessary to evaluate mental skills in these athletes at the same time as developing physical skills. Therefore, due to the lack of information about different psychological skills in Iranian elite swimmers and also the importance of using psychological skills by elite swimmers and the contradictions in this regard, the purpose of this study was to examine the psychological skills profile of Iranian elite swimmers based on competitive experience, gender, age group and swimming distance.

\section{Method}

The present study is an applied research in terms of purpose and non-experimental (causalcomparative) in terms of controlling variables. The statistical population of the present study included all male swimmers participating in the national club league in 1997 and elite female swimmers in the country. The statistical sample included 93 elite swimmers (73 male swimmers and 20 female swimmers) who agreed to cooperate with the researchers. It should be noted that a total of 170 questionnaires were distributed and finally 110 questionnaires were returned. Due to incomplete information of 17 questionnaires, the data of 93 questionnaires were extracted and analyzed. To analyze the findings in the present study, in addition to statistically describing the findings by calculating the mean and standard deviation, to 
statistically Statistical inference the findings, the normality and homogeneity of variances were examined and then parametric statistical methods including independent t-test. And non-parametric U-Whitney test was performed at a significant level of 0.05 with SPSS software version 23 .

\section{Data Gathering Tools}

A) Personal and contextual characteristics questionnaire: This questionnaire contained questions related to age, gender, the number of competitions approved by the federation in the last two years, the type of swimming discipline and the specialized distance of the swimmer.

B) Ottawa-3 Mental Skills Assessment Tool (OMSAT -3): This test is one of the most comprehensive tests of athletes' mental fitness, which measures twelve mental skills in three categories, basic psychological skills (goal setting, commitment, self-confidence). Measures psychophysical skills (stress response, stress control, relaxation and empowerment) and cognitive skills (concentration, concentration recovery, imagery, mental training and competition design). This questionnaire consists of 48 questions in the form of a 5-point Likert scale. In front of each sentence there are options agree, completely agree, disagree, completely disagree which are awarded points of one to seven respectively. Of course, the questions of the four factors of stress response, fear control, concentration, and concentration recovery are scored in reverse. Participants answer one of seven options based on their current or past status in competitions and training. As a result, the maximum score of each question is seven and the sum of the highest score of each of the twelve skills is 28. This questionnaire was developed at the University of Ottawa by John Salma, which was validated by Zeidabadi et al. In 2014 (34). This questionnaire had good fit indices, based on the analysis of the second-order confirmatory factor model $(\mathrm{RMSEA}=0.06, \mathrm{X} 2 / \mathrm{df}=3.05$ and $\mathrm{CFI}=$ 0.92. Also, its time reliability was 0.76 and its internal consistency was 0.91 ).

\section{Results}

The results of Kolmogorov-Smirnov test showed that the distribution of data in psycho-physical, cognitive and the general psychological skills was normal ( $\mathrm{P}<0.05)$; But in basic psychological skills was not normal $(\mathrm{P}<0.05)$. Therefore, to compare psycho-physical, cognitive and psychological skills used of independent t-test and to compare the basic skills used of the Mann-Whitney test at a significant level of 0.05 with SPSS software version 23.

As shown in Table 1, there is no a statistically significant difference between the psycho-physical skills of Iranian elite swimmers based on competitive experience $(\mathrm{P}=0.16)$, gender $(\mathrm{P}=$ $0.16)$, age category $(\mathrm{P}=0.22)$ and swimming distance $(\mathrm{P}=0.80)$. 
Table 1. Results of independent t-test to compare psycho-physical skills of Iranian elite swimmers based on competitive experience, gender, age group and swimming distance.

\begin{tabular}{|c|c|c|c|c|c|c|}
\hline Variables & \multicolumn{2}{|c|}{ Mean \pm SD } & $\mathbf{t}$ & df & P-value & Effect Size \\
\hline $\begin{array}{l}\text { Competitive } \\
\text { Experience }\end{array}$ & $\begin{array}{l}<7 \text { Competition } \\
78.10 \pm 75.10\end{array}$ & $\begin{array}{l}>7 \text { Competition } \\
80.12 \pm 44.95\end{array}$ & -1.15 & 91 & 0.16 & 0.014 \\
\hline Gender & $\begin{array}{c}\text { Female } \\
80.9 \pm 65.19\end{array}$ & $\begin{array}{c}\text { Male } \\
79.12 \pm 27.14\end{array}$ & 0.30 & 91 & 0.16 & 9.88 \\
\hline Age & $\begin{array}{c}13-14 \mathrm{yr} \\
80.8 \pm 96.68\end{array}$ & $\begin{array}{c}\geq 15 \mathrm{yr} \\
77.14 \pm 88.19\end{array}$ & 0.54 & $* * 72.50$ & 0.22 & 0.005 \\
\hline $\begin{array}{c}\text { Swimming } \\
\text { Distance }\end{array}$ & $\begin{array}{c}50,100 \mathrm{~m} \\
79.11 \pm 48.10\end{array}$ & $\begin{array}{c}>100 \mathrm{~m} \\
79.12 \pm 79.70\end{array}$ & -0.91 & 91 & 0.80 & 1.09 \\
\hline
\end{tabular}

Table 2. Results of independent t-test to compare cognitive skills of Iranian elite swimmers based on competitive experience, gender, age group and distance.

\begin{tabular}{|c|c|c|c|c|c|c|}
\hline Variables & \multicolumn{2}{|c|}{ Mean \pm SD } & $t$ & df & P-value & Effect Size \\
\hline $\begin{array}{l}\text { Competitive } \\
\text { Experience }\end{array}$ & $\begin{array}{l}<7 \text { Competition } \\
99.11 \pm 75.63\end{array}$ & $\begin{array}{c}\text { > 7 Competition } \\
101.13 \pm 27.59\end{array}$ & -0.70 & $* * 83.14$ & 0.19 & 0.005 \\
\hline Gender & $\begin{array}{c}\text { Female } \\
100.11 \pm 45.42\end{array}$ & $\begin{array}{c}\text { Male } \\
101.13 \pm 42.02\end{array}$ & -0.47 & 91 & 0.16 & 1.09 \\
\hline Age & $\begin{array}{c}13-14 \mathrm{yr} \\
101.10 \pm 88.64\end{array}$ & $\begin{array}{c}\geq 15 \mathrm{yr} \\
100.14 \pm 40.81\end{array}$ & 1.29 & $* * 65.09$ & 0.59 & 0.01 \\
\hline $\begin{array}{c}\text { Swimming } \\
\text { Distance }\end{array}$ & $\begin{array}{c}50,100 \mathrm{~m} \\
100.12 \pm 43.67\end{array}$ & $\begin{array}{c}>100 \mathrm{~m} \\
103.12 \pm 40.60\end{array}$ & -0.11 & 91 & 0.71 & 1.09 \\
\hline
\end{tabular}

As shown in Table 2, there is no a statistically 0.16), age category $(\mathrm{P}=0.59)$ and swimming significant difference between the cognitive distance $(\mathrm{P}=0.71)$. skills of Iranian elite swimmers based on competitive experience $(\mathrm{P}=0.19)$, gender $(\mathrm{P}=$

Table 3. Results of the Mann-Whitney test to compare basic mental skills based on competitive experience, gender, age group and distance.

\begin{tabular}{|c|c|c|c|c|c|}
\hline Variables & \multicolumn{2}{|c|}{ Mean } & $\mathbf{Z}$ & P-value & Effect Size \\
\hline $\begin{array}{c}\text { Competitive } \\
\text { Experience }\end{array}$ & $\begin{array}{c}<7 \text { Competition } \\
68.50\end{array}$ & $\begin{array}{c}>7 \text { Competition } \\
71\end{array}$ & -1.32 & 0.18 & 0.13 \\
\hline Gender & $\begin{array}{c}\text { Female } \\
70\end{array}$ & $\begin{array}{l}\text { Male } \\
69.50\end{array}$ & -0.14 & 0.88 & 0.01 \\
\hline Age & $\begin{array}{c}13-14 \mathrm{yr} \\
69\end{array}$ & $\geq \underset{71}{15 \mathrm{yr}}$ & -0.7 & 0.48 & 0.07 \\
\hline $\begin{array}{l}\text { Swimming } \\
\text { Distance }\end{array}$ & $\begin{array}{c}50,100 \mathrm{~m} \\
69\end{array}$ & $\begin{array}{c}>100 \mathrm{~m} \\
71\end{array}$ & -0.79 & 0.42 & 0.07 \\
\hline
\end{tabular}

As shown in Table 3, there is no a statistically significant difference between the basic psychological skills of Iranian elite swimmers based on competitive experience $(\mathrm{P}=0.18)$, gender $(\mathrm{P}=0.88)$, age category $(\mathrm{P}=0.48)$ and swimming distance $(\mathrm{P}=0.42)$.
As shown in Table 4, there is no a statistically significant difference between the general psychological skills of Iranian elite swimmers based on competitive experience $(\mathrm{P}=0.36)$, gender $(\mathrm{P}=0.22)$, age group $(\mathrm{P}=0.27)$ and swimming distance $(\mathrm{P}=0.96)$. 
Table 4. Independent t-test results to compare the general psychological skills of elite Iranian swimmers based on competitive experience, gender, age group and distance.

\begin{tabular}{|c|c|c|c|c|c|c|}
\hline Variables & \multicolumn{2}{|c|}{ Mean \pm SD } & $\mathbf{t}$ & df & $\begin{array}{c}\text { P- } \\
\text { value }\end{array}$ & Effect Size \\
\hline $\begin{array}{l}\text { Competitive } \\
\text { Experience }\end{array}$ & $\begin{array}{c}<7 \text { Competition } \\
244.28 \pm 88.87\end{array}$ & $\begin{array}{c}>7 \text { Competition } \\
252.32 \pm 53.19\end{array}$ & -1.120 & 91 & 0.36 & 0.01 \\
\hline Gender & $\begin{array}{c}\text { Female } \\
249.25 \pm 80.24\end{array}$ & $\begin{array}{c}\text { Male } \\
248.32 \pm 25.06\end{array}$ & -0.200 & 91 & 0.22 & 4.39 \\
\hline Age & $\begin{array}{c}13-14 \mathrm{yr} \\
251.35 \pm 86.40\end{array}$ & $\begin{array}{c}\geq 15 \mathrm{yr} \\
244.37 \pm 60.72\end{array}$ & 1.092 & $* * 65.072$ & 0.27 & 0.002 \\
\hline $\begin{array}{c}\text { Swimming } \\
\text { Distance }\end{array}$ & $\begin{array}{c}50,100 \mathrm{~m} \\
274.29 \pm 26.93\end{array}$ & $\begin{array}{c}>100 \mathrm{~m} \\
251.32 \pm 64.43\end{array}$ & 0.611 & 91 & 0.96 & 0.003 \\
\hline
\end{tabular}

\section{Discussion and Conclusion}

One of the most important factors affecting the optimal performance of motor skills and achieving peak performance in sports and competitive environments is the use of psychological skills (Weinberg et al., 2003; Jones et al., 1990; Gazzi et al., 2009; Taylor et al., 2008). The findings of the present study showed that there is no difference between the psychological skills profile of Iranian elite swimmers based on competitive experience. As regards that no research was found on the psychological skills of swimmers based on competitive experience, the results of the present study in this section were compared and discussed with the research results of other individual disciplines. The results of the present study in this section contradict the results of the research of Bebetsas et al. (2015) who stated that there is a relationship between the level of competitive experience of archery athletes and their psychological skills and athletes are more experienced, have more confident and focused and tend to let go of worries and pressure to perform. In this regard, the results of Patrick (2014) study that examined the use of psychological skills by athletes in high-risk disciplines and the effect of experience on the use of these skills; Showed that experienced athletes used significantly more psychological skills than inexperienced athletes. Possible reasons for the contradiction between the results of the present study and previous research can be mentioned to the psychological needs and demands of the sport, the practice of regular mental skills by athletes, and the definition of competitive experience; in the present study, the number of competitions was considered as a competitive experience, while in the previous research, the competitive experience was the number of years of presence at the competitive level.

The findings of the present study also showed that there is no difference between the profile of psychological skills of Iranian elite swimmers based on gender. Given that no research has been found on the differences between gender-based psychological skills specifically for swimmers; the results of the present study in this section were compared with the results of research conducted in individual disciplines. Malika Sharma et al. (2010) did not observe a significant difference between the psychological skills of men and women in male and 
female gymnasts at the inter-university championship level. Jana et al. (2015) also examined the psychological profile of Indonesian male and female swimmers and stated that there is no difference between the psychological profile of male and female swimmers, which is consistent with the results of the present study in this section. To assess the level of psychological skills of Iranian elite swimmers based on gender, the scores obtained by male and female swimmers in each of the twelve psychological skills of Amest were compared with the norm presented by Zeidabadi et al. (2014). Accordingly, Iranian elite male swimmers in the psychological skills of "targeting", "stress response", "fear control", "empowerment", "concentration", " concentration recovery", "illustration", and "competition design" were in good condition and in skills "confidence", "commitment", "relaxation", "mental training" were moderate condition. Also elite Iranian female swimmers in "concentration recovery" skills were excel and in "targeting", "stress response", "commitment", "fear control", "concentration", and "racing" were in good condition, in "confidence", "relaxation", "empowerment" and "illustration" were in moderate condition, and in "mental training skills were in weak condition ".

The results of the present study also showed that there is no difference between the profile of psychological skills in Iranian elite swimmers by age group. Given that no research has been found on the differences between age-specific psychological skills specifically for swimmers; the findings in this section were compared with the results of research conducted in individual disciplines. Tejari (2012) in a study compared the psychological profile of elite male judo in Iran using the Mental Readiness Questionnaire of the South Australian Sports Institute in three age groups: adults (22-32 years), youth (17-21 years) and adolescents (12-16 years). The results showed that there was no significant difference between the three age groups in terms of mental skills (motivation, concentration, self-confidence, mental energy level regulation, mental imagery, and goal setting) and in all three age groups, the level of psychological skills of motivation, self-confidence and goal setting were at a high level and mental skills of concentration, control of mental states and mental imagery were at a good level. Shojaei et al. (2009) also stated that there is no significant difference between the basic psychological, the psycho-physical and cognitive skills of wrestlers of different age groups, which is consistent with the results of the present study. In this regard, Shojaei et al. (2009) stated that due to the importance of psychological skills from the perspective of wrestlers in different age groups to practice and participate in competitions, wrestlers in different age groups try to maintain psychology skills at desired level, This has led to a lack of statistically significant differences in psychological skills in different age groups. However, considering that most of the psychological skills of Iranian elite swimmers were moderate and weak; It can be said that elite Iranian swimmers do not believe much in the effect of psychological skills on their performance and do not care about it; For this reason, there is no statistically significant difference between the profile of psychological 
skills of Iranian elite swimmers in different age groups.

The results of the present study in this section are inconsistent with the results of Bebetsos and Antonio (2003) who stated that the ability to respond to stress in adults was higher than the adolescent badminton and also the results of research by Ghadiri et al. (2016) who stated that psychological skills (respond to stress) of adult wushu and cognitive skills and concentration of adult kickboxing were superior to young athletes in both disciplines. It seems that the psychological demands required in badminton and martial arts as an open skill compared to swimming as a closed skill, as well as the wide age range of 13 to 50 years considered in the research of Bebetsus and Antonio, are the reason for contradiction of research results with current research results.

Also, the results of the present study showed that there is no statistically significant difference between the profile of psychological skills of elite Iranian swimmers based on swimming distance. Gaini (2006) in a study aimed at investigating the relationship between mental fitness indices (motivation, emotion control, concentration, selfconfidence) in swimmers with a record of speed swimming (50 meters) and endurance swimming (200 meters) in the age group (9-17), stated that there is no significant difference between any of the indicators of mental fitness of swimmers with the record of speed and endurance swimming, which is consistent with the results of the present study. He attributed the reasons for the discrepancy to the selection of elite swimmers regardless of the structures of mental fitness, the young age of the subjects and the long camp time and of course the negative impact of factors such as distance from family, hard and continuous training and uniformity of the environment on mental health, the lack of presence of a sports psychologist coach and the lack of adequate training of coaches in this area. In this regard, Kaya et al. (1999) stated that there is no difference between the psychological skills of elite male and female student swimmers in speed and endurance.

Despite this fact that psychological skills are important factors in the success of athletes at high levels of sport; Based on the results of the present study, it seems that Iranian elite swimmers have learned psychological skills through natural learning, and this has caused most of the psychological skills of Iranian elite swimmers to be moderate and low. Therefore, elite swimmers, club officials and the swimming federation are advised to make the necessary plans using experts in the field of sports psychology to learn and improve the level of mental skills.

\section{References}

1. Bohlul, A; Tahmasebi Broujeni, SH; Ezzati, R. (2015). Psychological Strategies Athlete Females and Males in Individual and Team Sports. Sport psychological studies. (12). Pp. 73-84.

2. Esfahani, N; Ghazal Safloo, H. (2013). Comparison of psychological skills of Elite and non-Elite Karate ka and its relation with athletes performance. Psychological studies .No. 1, 09, 110-119.

3. Gaeini, Abbas Ali; Arazi, Hamid; Lari, Ali Asghar; Khaledi, Neda. (2006). Relationship between psychological paremeters of Talent Identification in Swimming, Sprint and Endurance Performance, Of Iranian Elite Swimmers. Psychological Research . (9). Pp. 45-55.

4. Ghadiri, F; Nemati, M; Foroozande, Z. (2018). Psychological sciences. No. (23). 17-34.

5. Jafari, A; Moradi, MR; Rafieinia, P. (2007). A Comparison of psychological skills of Elite and non- 
Elite Men and Female Taekwondo players. Universal Sport science Journal.(6)32-38.

6. Mihan Doost, Hedayat. (2001). Comparison of psychological skills of Elite and non-Elite volleyball players. Institute of physical education: Tarbiat Moallem of Tehran ( Upbringing the teacher of Tehran University). Movement and Sport Science, 1(2), 70-80.

7. Mirzaee, Bahman; Rahmani Nia, Farhad; Brdar, Farshad. (2007). Comparison of psychological skills of National wrestlers team, in free style and foreign wrestling. Journal of movement, (34) 69-82.

8. Shojaee, M; Danesh Far, A; Rahmati, A. (2010). The effect of age on Freestyle wrestlers' psychological skills. Sport sciences quarterly. Sport Sciences. No. 4, Volume 2, 11-29.

9. Taghian ,F; Bahram, A. (2010). Comparison of psychological skills of Elite and non-Elite female volleyball player. Iranian congresses articles, (2), 72-90.

10. Tojari, F. (2012). Comparison and determination of psychological profiles of Iran's elite male judoka for talent identification and development (TID). Applied Research in Management and biology sciences. (2). Pp. 53-60

11. Zeidabadi, R; Najafipour, F. (2015). The comparison of elite and non-elite martial athletes' mental skills profile. No. 22. Volume, 6. Pp. 67-80.

12. Zeid Abadi, R; Rezayi, F; Motesharrei, I. (2014). Psychometric Properties and Normalization of Persian Version of Ottawa Mental Skills Assessment Tools (OMSAT-3). Sport psychological studies. Sport psychological studies. No. 7, Pp.63-83.

13. Ackland T. (1999). Talent identification: What makes a champion swimmer? The University of Western Australia, Stand alone, 67-74.

14. Adams, L, B., Smith \& Daniel,E. (1991). A Comparative analysis of Cognitive difference among female elite and no elite high school Field Hockey Players and High School Physical Education Class Non athletes. Master's Theses Department of Physical Education and Sport State University of New York College at Brockport .

15. Anshel, Mark H. (2007). An examination of selfregulatoty cognitive- Behavioural strategies of Australian elite and non-elite competitive male swimmers. physical education \& sport sciences, 30(2), 83-78.

16. Bagozzi RP. (1992). The self-regulation of attitudes, intentions and behaviour. Social Psychology Quarterly, 55, 178-204.

17. Bebetsos, E. (2015). Psychological skills of elite archery athletes. Journal of Human Sport \& exercise. 10(2), 623628.

18. Bebetos,E \& Antonious, P. (2003). Psychological skills of Greek badminton athletes. Perceptual and motor skills, 97(3), 89-96.

19. Burton D. (1989). Winning isn't everything: The impact of performance goals on collegiate swimmers' cognitions and performance. The Sport Psychologist, 3(2), 105-132.

20. Calmels ,C., Fournier ,J., D'Arripe, F, Soulard, A . (2003). Competitive strategies among elite female gymnasts: An exploration of the relative influence of psychological skills training and natural learning experiences. International Journal of Sport and Exercise Psychology ,1(4), 327-352.

21. Cox, .H R, Liu Z. (1996). Psychological skills of elite Chinese athletes. Journal of Sport Psychology, 27(2) ,123-132.

22. Fletcher, DH,S. (2001). The relationship between psychological skills usage and competitive anxiety responses. Psychology of Sport \& Exercise. (2), 89-101.

23. Géczi, G., Tóth, L., Sipos, K., Fügedi, B., Dancs, H., \& Bognár, J. (2009). Psychological profile of Hungarian national young ice hockey players. Kinesiology, 41(1), 88-96.

24. Gucciardi, DF., Gordon, S, \& Dimmock, JA. (2008). Towards an understanding of mental toughness in Australian football. Journal of Applied Sport Psychology .No. 3, volume 20, Pp. 261-281.

25. Hale, BD., \& Whitehouse, A. (1998). The effects of imagery-manipulated appraisal on intensity and direction of competitive anxiety. Reasearchgate, 12(1), 40-51.

26. Hanton, S., \& Jones, G. (1996). The acquisition and development of cognitive skills and strategies: I. Making the butterflies fly in formation. The Sport Psychologist, 13(1), 1-21.

27. Jannah, M., Mulyana, OP., Muthohir, TC. (2015). Psychological profiles of Indonesian elite swimmers. Malaysian Journal of Movement, Health \& Exercise, $4(2)$.

28. Jones, J., \& Hardy, L.E. Wiley, C. (1990). Stress and Performance in Sport. England, Sport \& Reaction, 81106.

29. Kirschenbaum, Daniel, S. (1987). Self-regulation of sport performance. Medicine \& Science in Sports \& Exercise, 19(5), 106-113.

30. Kizildag, E., Tiryaki, MS. (2012). Imagery use of athletes in individual and team sports that require open and closed skill. Percept Mot Skills, 114(3), 748-756.

31. Leunes, AD., \& J.R. (2002). Sport Psychology - An Introduction of sport psychology, 15(5), 24-40.

32. Marcus, K., Taylor University, Michigan State University \& Cristina Rolo University. (2008). Performance strategies of US Olympians in practice and competition. High Ability Studies, 19(1), 19-36.

33. Malika, sharma \& Lalit, sharma M. (2010). Psychological Skills Differences Between Male and Female Indian Gymnasts. Indian Journal of Physical Education \& Sports Sciences, 1(1), 5-20.

34. Munroe-Chandler, KJ., Hall, C.R., Fishburne, G., Murphy, L., \& Hall, N. D. (2012). Effects of a cognitive specific imagery intervention on the soccer skill performance of young athletes: Age group comparison. Psychology of sport and exercise, 13(3), 324-331.

35. Patrick R. Young. \& Knight, Erin L. (2014) "Use of Psychological Skills by Risk Sport Athletes". Journal of Human Performance in Extreme Environments. 11(2).

36. Paulo Simões, JV-R., António Silva, Helder, M. Fernandes. (2012). Effects of a Process-Oriented Goal Setting Model on Swimmer's Performance. Human Kinetics, 32(1), 65-76.

37. Thiese, Kaia.E., Huddleston Sharon. (1999). The Use of Psychological Skills by Female Collegiate Swimmers. Journal of Sport Behavior. No. 4, volume 22, P.602. 
38. Volp, A., \& Keil, U. (1987). The relationship between performance, intention to drop out, \& intrapersonal conflict in swimmers. Journal of Sport \& exercise Psychology, 9(1), 358-375.

39. Weinberg R. (2009). Handbook of sports medicine and science Sussex: Wiley-Blackwell Publishing.

40. Weinberg R., Butt, J., Knight, B. (2003). The relationship between the use and effectiveness of imagery: an exploratory investigation Journal of Applied Sport Psychology, 15(1), 26-40. 